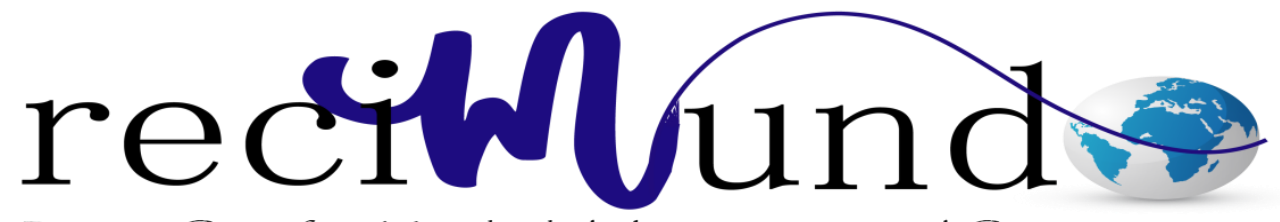

Revista Científica Mundo de la Investigación y el Conocimiento

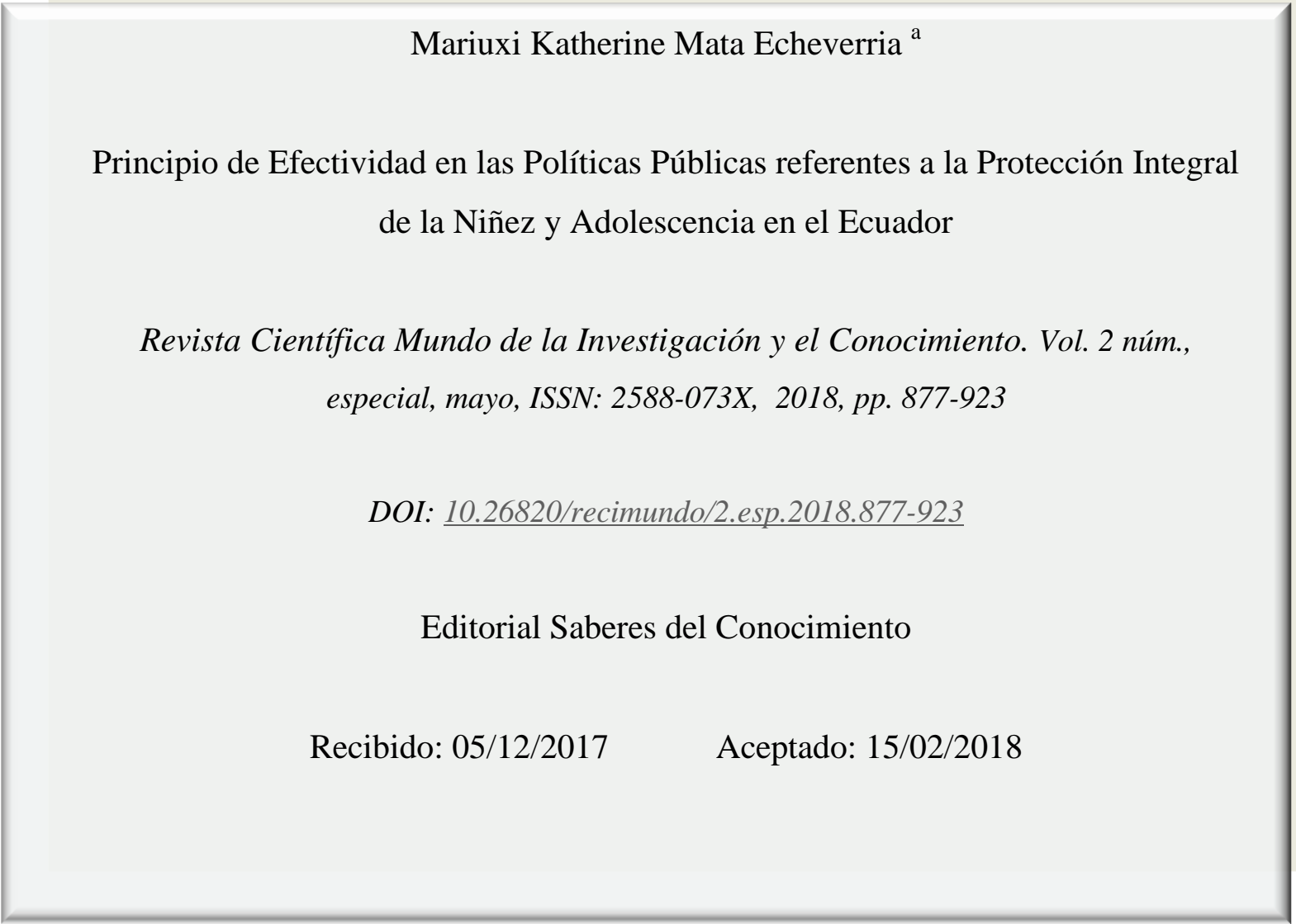

a. Universidad de Guayaquil; mariuxi.matae@ug.edu.ec 


\section{Principio de Efectividad en las Políticas Públicas referentes a la Protección Integral de la Niñez y Adolescencia en el Ecuador}

Vol. 2, núm. Esp., (2018)

Mariuxi Katherine Mata Echeverria

\section{RESUMEN}

La Protección Integral de la Niñez y Adolescencia, ha pasado de ser un paradigma a ser un principio con un enfoque evidentemente deleznable, difícil de ser cumplido en el Ecuador, luego en que las Acciones Afirmativas que la Constitución de la República ha establecido en sus líneas normativas, resulta tarea difícil asumir para el Estado una responsabilidad que históricamente ha arrojado los índices más preocupantes de los grupos vulnerables de nuestra sociedad, y más aún en la actualidad cuando esos índices, que aunque muchos ya han disminuido, existen nuevos enemigos del desarrollo integral de la Niñez y Adolescencia, que se presentan como las nuevas cifras agobiantes del sector más olvidado en los últimos tiempos en nuestro país.

Una Acción Afirmativa, no puede estar aislada de la ejecución de políticas públicas, caso contrario se convierte en letra muerta, como lo que se puede observar en la norma, así pierden absolutamente toda su esencia, pues éstas deben encontrar eco en la elaboración de postulados para la consecución de las garantías constitucionales que deberán estar encaminadas, siempre, a corregir las discriminaciones contra ciertos grupos olvidados de la sociedad.

La indiferencia ante una necesidad emergente de implementación de políticas públicas certeras, podría llegar a convertir en un axioma no lógico o un postulado que ya viene dando qué decir en algunos países de Latinoamérica, una acción afirmativa puede convertirse en negativa...

Palabras claves: Protección integral, acciones afirmativas, niñez, adolescencia, políticas públicas. 


\title{
Principio de Efectividad en las Políticas Públicas referentes a la Protección Integral de la Niñez y Adolescencia en el Ecuador
}

Vol. 2, núm. Esp., (2018)

Mariuxi Katherine Mata Echeverria

\begin{abstract}
The Integral Protection of Children and Adolescents, has gone from being a paradigm to being a principle with an obviously deleznable approach, difficult to be fulfilled in Ecuador, then the Affirmative Actions that the Constitution of the Republic has established in its lines normative, it is a difficult task to assume for the State a responsibility that historically has thrown the most worrying indices of the vulnerable groups of our society, and even more so now when those indices, which although many have already decreased, there are new enemies of integral development of Childhood and Adolescence, which are presented as the new crippling figures of the most forgotten sector in recent times in our country.
\end{abstract}

An Affirmative Action can not be isolated from the execution of public policies, otherwise it becomes a dead letter, as what can be observed in the norm, thus they lose absolutely all their essence, since they must find an echo in the elaboration of postulates for the attainment of constitutional guarantees that should be aimed, always, at correcting the discriminations against certain forgotten groups of society.

The indifference to an emerging need for the implementation of accurate public policies, could become a non-logical axiom or a postulate that is already giving something to say in some Latin American countries, an affirmative action can become negative ...

Keywords: Comprehensive protection, affirmative actions, childhood, adolescence, public policies. 


\section{Principio de Efectividad en las Políticas Públicas referentes a la Protección Integral de la Niñez y Adolescencia en el Ecuador}

Vol. 2, núm. Esp., (2018)

Mariuxi Katherine Mata Echeverria

\section{Introducción.}

\section{Evolución histórica}

El menor de edad ha sido considerado a lo largo de milenios sin una personalidad propia, diferenciada, sin un valor autónomo y, por tanto, careció de un derecho que regulara su circunstancia personalísima, es decir, no era visto como un sujeto de derechos, sino, como un objeto de derechos, que si bien es cierto, habían normas que regulaban su protección, más se desconocía su calidad de ser humano.

En la antigüedad, ahogada la personalidad de los menores por un indiscutible adultismo, se contemplaba a aquellos desde la perspectiva de un absoluto sometimiento a sus mayores y sin que se les atribuyese ninguna importancia. Al nacer solía ser examinado por una comisión de ancianos que determinaban su extinción si no era idóneo para desempeñar la futura condición de soldado o de ciudadano.

Durante la época de la dominación romana, asume la familia una gran importancia, pero el hijo queda sujeta completamente al pater-familiae, que investido de una soberanía absoluta y de un poder ilimitado, era el administrador del patrimonio familiar y el sacerdote del culto especial de su casa. Aún en los primeros tiempos ejercía la función de juzgar a su hijo, a quien incluso podía condenar a muerte.

El cristianismo iluminará con una nueva luz la existencia del hijo, reconociéndole un valor y un significado original. La familia será contemplada en función de los hijos y de su educación. El Nuevo Testamento puede ser considerado como la primera Declaración de los 


\section{Principio de Efectividad en las Políticas Públicas referentes a la Protección Integral de la Niñez y Adolescencia en el Ecuador}

Vol. 2, núm. Esp., (2018)

Mariuxi Katherine Mata Echeverria

Derechos del Niño, en cuanto que vino a santificar el derecho fundamental de su libertad y de su dignidad, al exigir el respeto debido a su persona. Será con el cristianismo cómo la infancia conquista no sólo un valor y significado por sí misma, sino la explícita declaración de su predilección. En su típica simplicidad y transparencia, se presenta a los niños como un modelo a imitar.

El movimiento iluminista del siglo XVII reafirma explícitamente el derecho del niño a la libertad y, en su consecuencia, al respecto debido a la naturaleza y a las características propias de la infancia. Baste recordar que su más significativo representante, Juan Jacobo Rousseau, sostenía el valor absoluto de la personalidad del niño, en su significado de autenticidad y de autonomía, y que como sujeto de exigencias, de modo de vida, presentaba un ritmo de desarrollo propio y particular. Así mismo, Rousseau siendo un filósofo y no un pedagogo, dejó un importante avance en cuanto a la educación de los niños, es por eso que se le considera como el representante típico del tratamiento individual en la educación. Una de las importantes claves de Rousseau es diferenciar a niños y adultos en cuanto a su aprendizaje. Hasta su época se educaba a los niños como si fueran adultos en pequeño. Para Rousseau la infancia tiene maneras de ver, de pensar, de sentir que le son propias igualmente la adolescencia. Los maestros deben tener en cuenta esas diferencias, conocerlas y respetarlas. En la educación, el niño ha de permanecer en su naturaleza de niño. La educación, debe ser gradual. El educador debe esperar con confianza la marcha natural de la educación e intervenir lo menos posible en el proceso de la formación. La educación del niño debe comenzar desde su nacimiento y debe impedirse que adquiera hábitos de los cuales pudiera llegar a ser esclavo. La educación religiosa, no debe ser confesional y debe realizarse, no es la infancia, sino en la edad de la razón. En su libro "El Contrato Social", rescata 


\section{Principio de Efectividad en las Políticas Públicas referentes a la Protección Integral de la Niñez y Adolescencia en el Ecuador}

Vol. 2, núm. Esp., (2018)

Mariuxi Katherine Mata Echeverria

la necesidad de las personas, durante toda su vida, de consejo y guía. En su texto "El Emilio", atacó al sistema educativo de su época, pues mantiene que los niños deben ser educados a través de sus intereses y no por la estricta disciplina. (Salanova Sánchez, 2010)

Es evidente también, que los Derechos del hombre, en cuanto a tal, no tendrían tampoco un reconocimiento explícito hasta el año 1776, en que en Filadelfia, el 4 de julio, se proclama solemnemente la Declaración de Independencia de las colonias norteamericanas, en la que se recogieron todos los principios formulados anteriormente por las corrientes enciclopedistas, y posteriormente en la Declaración de los Derechos del Hombre y del Ciudadano que enarbolaría programáticamente la Revolución Francesa.

Al positivismo de la segunda mitad del siglo XIX, le corresponde el mérito de haber fundamentado su base experimental en el estudio de la biología, de la medicina, de la psicología y de la ciencia jurídica, para poder revelar el precioso secreto de la naturaleza y de la vida humana y muy particularmente de las del niño.

El menor vería, en el siglo xx, reconocidos sus derechos fundamentales al impacto de la revolución pedagógica, iluminada por el progresivo avance de los conocimientos médicopsicológicos, cuya legitimación proporcionaría la doctrina iusnaturalista. Así la nueva concepción del menor, no establecida en función de la edad adulta o de la sociedad, sino en el significado evolutivo de una personalidad en formación, en el de la dignidad y respeto que su persona ostenta y merece y en la esperanza que para la Humanidad representa este colectivo, sería el fundamento esencial y la fuente que inspiraría la primera Declaración de los Derechos del Niño, adoptada el 24 de septiembre de 1924 en la V Asamblea de la Sociedad de las 


\section{Principio de Efectividad en las Políticas Públicas referentes a la Protección Integral de la Niñez y Adolescencia en el Ecuador}

Vol. 2, núm. Esp., (2018)

Mariuxi Katherine Mata Echeverria

Naciones, y que representó una declaración de principios que fue más allá de las previsiones que estableciera el Tratado de Versalles, en donde se prevé en su preámbulo la protección de los niños, jóvenes y adolescentes. (DÍAZ RUIZ DE SIEKAVIZZA , 2014)

Empero, la consideración del menor y la de su posición jurídica y social fue el fruto de una larga maduración histórica del pensamiento, del comportamiento y de una común y generalizada toma de conciencia que cristalizaría, a nivel universal, por la ratificación unánime del texto de la Declaración de todos los Estados que formaron parte de la Sociedad de las Naciones.

El conocimiento científico en el siglo XX ha progresado sensiblemente, no ya por los aportes de los siglos anteriores, sino porque los saberes proco.médico-pedagógicos incidirían, para enriquecerle, en el ámbito de lo jurídico y ante el carácter universalista de las nuevas concepciones jurídicas resultantes, éstas al proyectarse hacia la protección de la minoridad, trascenderían al terreno de la convivencia internacional y harían que la aspiración que se dirige a hacer más efectiva aquella protección, se concretara en salvaguardar a los menores contra el peligro que la destrucción de los valores humanos, consecuencia de las dos últimas contiendas mundiales, pudiera volver a producirse, con el consiguiente riesgo para el colectivo humano más desvalido y dependiente. Será así como llegarán a adoptar los documentos internacionales relativos a los derechos de la minoridad.

Estos documentos pueden ser clasificados como generales o universales o como regionales, en razón al ámbito más o menos extenso de su aplicación territorial. Y en públicos y 


\section{Principio de Efectividad en las Políticas Públicas referentes a la Protección Integral de la Niñez y Adolescencia en el Ecuador}

Vol. 2, núm. Esp., (2018)

Mariuxi Katherine Mata Echeverria

privados en función del carácter gubernamental o no gubernamental del organismo del que emanan.

En función de su contenido, todos los documentos internacionales que hacen referencia a los menores son la expresión de principios inmutables de justicia que todos los pueblos del mundo debieran reconocer y acatar. Se trata de unas reglas que pertenecen al orden del Derecho permanente.

Todo lo que las nociones del Derecho y del orden público puedan tener, respectivamente, de variables y relativas, está basado en unos criterios de interpretación diversa que, a primera vista, parece imposible que puedan ser reducidas a fórmulas absolutas y universales, pero si se tiene en cuenta que al regular la protección del menor, esta protección se fundamenta en las circunstancias personalísimas e inexorables que concurren en quien es sujeto pasivo de aquella, presenta dicha regulación unas notas de permanencia y de absoluto que derivan esencialmente de esas exigencias inmutables de la justicia tutelar.

Tutela Jurídica de la protección de los derechos de la niñez y adolescencia en los Acuerdos Internacionales

Los Derechos del niño, por su naturaleza son derechos humanos, estos le pertenecen inclusive antes de su nacimiento, en este sentido en el presente artículo se referirá entonces al nasctiturus, término jurídico con el que se designa a la criatura que se encuentra en el vientre materno, es decir que habiendo concebido aún no ha nacido. 


\section{Principio de Efectividad en las Políticas Públicas referentes a la Protección Integral de la Niñez y Adolescencia en el Ecuador}

Vol. 2, núm. Esp., (2018)

Mariuxi Katherine Mata Echeverria

El nasciturus carece de personalidad jurídica. Sin embargo, considerándose que en el futuro pueda tenerla, el estado le reconoce una serie de derechos subjetivos, lo que hace que sea protegido por la legislación, pues se le considera un bien jurídico necesitado de tutela.

Cabe destacar que el reconocimiento de los derechos del nasciturus, empezó en Roma, indistintamente de no ser considerado como persona se le reconocía ciertos derechos como por ejemplo: si la mujer embarazada estaba condenada a muerte, la ejecución se posponía hasta el nacimiento. También si el padre del nonato era senador al momento de la concepción, este nacía con los privilegios de hijo de senador.

Desde el siglo XIX han surgido varias organizaciones, a nivel internacional y nacional, que promueven la protección del niño. La mayoría de ellas surgieron a fines de esa centuria y comienzos de la siguiente, como Save the Children. Las primeras nociones de reconocimiento de los derechos de la niñez, aparecieron durante el siglo XIX, a través de escritos que circularon en diversos medios de difusión intelectual de la época, tal es el caso de la Obra - El Niño-, realiza una profunda y clara reflexión sobre los derechos de la niñez, años más tarde Kate D Wiggin publicó Children’s Rights, obra en la que enfatiza los derechos de los niños y los principios sobre los cuales se sustenta la protección de sus derechos. (Observatorio de los Derecho de la Niñez y la Adolescencia, 2012)

En el siglo XX las políticas públicas se han visto fuertemente influidas por la acción de la Organización Internacional del Trabajo, sobre todo en relación con el trabajo o explotación infantil, y luego por la UNICEF, en torno a la alimentación y la escolarización. 


\section{Principio de Efectividad en las Políticas Públicas referentes a la Protección Integral de la Niñez y Adolescencia en el Ecuador}

Vol. 2, núm. Esp., (2018)

Mariuxi Katherine Mata Echeverria

Es preciso citar, la primera Declaración de los Derechos del Niño del 24 de Septiembre de 1924, conocida como La Declaración de Ginebra, contiene todos los principios fundamentales relativos a la protección de la infancia, al establecer en su redacción definitiva (UNICEF, 2006):

Siendo la primera declaración sobre los derechos del niño, de carácter sistemática, La Declaración de Ginebra de 1924, presentada a continuación, redactada por Eglantyne Jebb, fundadora de la organización internacional Save the Children..

Por la presente declaración de los Derechos del Niño, los hombres y las mujeres de todos los países reconocen que la humanidad debe dar al niño lo que ella tiene de mejor; afirman sus deberes al margen de toda consideración de raza, nacionalidad y creencia:

I. El niño debe ser puesto en condiciones de desarrollarse de una manera normal, material y espiritualmente.

II. El niño hambriento debe ser alimentado; el niño enfermo debe ser asistido; el retrasado debe ser estimulado; el extraviado debe ser conducido; el huérfano y el abandonado deben ser recogidos y socorridos.

III. El niño debe ser el primero en recibir socorros en época de calamidad.

IV. El niño debe ser dotado de medios con que ganarse su vida, y debe ser protegido contra toda explotación.

$V$. El niño debe ser educado en el sentimiento de que sus mejores cualidades deben ser puestas al servicio de sus hermanos. 


\section{Principio de Efectividad en las Políticas Públicas referentes a la Protección Integral de la Niñez y Adolescencia en el Ecuador}

Vol. 2, núm. Esp., (2018)

Mariuxi Katherine Mata Echeverria

Y por otro, también se instauró la primera Unión Internacional de Protección de la Infancia, UIPI. La creación de ambas instancias, incidió directamente para que en 1948, como parte de la aprobación de la Declaración Universal de los Derechos Humanos, en el artículo 25, se establezca que la infancia también tiene "derecho a cuidados y asistencia especiales". Este avance fue clave ya que dejó sentado un precedente para que una década más tarde se reconozcan ciertos derechos de la niñez, con independencia y especificidad propia frente a los de los adultos. Fue así como, en 1959, y siempre con la incidencia tanto de la UIPI como de UNICEF, la Asamblea General de las Naciones Unidas aprobó una segunda Declaración de los Derechos del Niño. En ella se recogieron los primeros postulados, aquellos propuestos por Eglantyne Jebb, y, a la vez, se reconocieron por primera vez algunos derechos específicos para la infancia. Entre éstos figuraban: el derecho a la libertad; contra la discriminación; a tener un nombre y una nacionalidad; a la educación; a la atención de la salud; y a una protección especial. A pesar de que estos reconocimientos, significaron un importante avance en el tránsito hacia los derechos, la Declaración de 1959 seguía basada en la así llamada Doctrina de Situaciones Irregulares. Es decir, en una concepción que priorizaba la intervención y corrección estatal y social a los niños, niñas y adolescentes, sin reconocer su autonomía y menos aún su condición de sujetos de derechos. Esta doctrina estaba inspirada en la creación del primer Tribunal de Menores a finales del siglo XIX. Partía de la premisa de que la niñez y adolescencia, al ser una etapa previa a la adultez, requería de la intervención directa del Estado o de la familia para asegurar la formación de individuos rectos, obedientes, productivos, que sean útiles a la sociedad y que reproduzcan el orden social establecido. Así, la primera etapa vital de todo ser humano, era considerada, en términos generales, como menor, menos válida y, poco o nada útil para la 


\section{Principio de Efectividad en las Políticas Públicas referentes a la Protección Integral de la Niñez y Adolescencia en el Ecuador}

Vol. 2, núm. Esp., (2018)

Mariuxi Katherine Mata Echeverria

sociedad. Por lo tanto, el presente de esa minoridad interesaba en la medida en que el Estado y la sociedad intervengan para reformar a esos "menores" que en el futuro tendrían cabida en el espacio público al llegar a una etapa mayor y "seria", que era la adultez. Dentro de esta doctrina se estipulaban dos posibles situaciones para los menores de edad: 1- una situación de regularidad o normalidad, en la cual esa intervención y formación estaba a cargo del núcleo familiar, específicamente de la madre, y, 2- una circunstancia de irregularidad o anormalidad, donde los "menores", al quedar fuera del núcleo familiar, en condiciones de abandono, en la calle, en peligro, pobreza o delincuencia, debían necesariamente ser intervenidos por otras instituciones públicas que modifiquen y prevengan cualquier posible irregularidad en su comportamiento futuro. Así, y bajo esta doctrina, se daba paso a un modelo estatal -y también social- tutelar, proteccionista, reformador e incluso paternalista hacia los niños, niñas y adolescentes, quienes por ser considerados como seres desvalidos, e incluso "incompletos", requerían de la permanente vigilancia, control y corrección tanto en el espacio público como en el privado. En la Declaración Universal de los Derechos del Niño (1959), en ella se consagra la necesidad de proporcionar al niño una Protección especial. Con el criterio de que los derechos del niño deberían estar enunciados en una carta especial que los garantice y proteja, la Asamblea General de la ONU, aprobó en 1959 una Declaración de los Derechos del Niño, que constaba de 10 principios, previo a ello en el año de 1953, había decidido que el Fondo Internacional de Emergencias de las Naciones Unidad para los niños (UNICEF), continuará prestando su contingente en calidad de organismo especializado y permanente para la protección de la infancia, denominándolo oficialmente Fondo de las Naciones Unidas para la Infancia 


\section{Principio de Efectividad en las Políticas Públicas referentes a la Protección Integral de la Niñez y Adolescencia en el Ecuador}

Vol. 2, núm. Esp., (2018)

Mariuxi Katherine Mata Echeverria

Más adelante surgen Las Reglas Mínimas de las Naciones Unidas para la administración de la Justicia de Menores (Reglas de Beijín) año 1985. Contiene orientaciones básicas con fines de prevención del delito, así como las reglas para procesar a los menores que incurran en delitos.

La promulgación de la Convención del 1989 Sobre los Derechos del Niño, ha sido el punto de partida para que muchos de los estados suscribientes, incorporen en sus ordenamientos jurídicos internos, normativas especializadas que buscan proteger y garantizar los derechos inherentes a la niñez y adolescencia, en la mayoría de los casos estos derechos han sido elevados a la categoría de fundamentales y constitucionales. En ese mismo año, una renovada campaña internacional a favor de los derechos de la infancia culminó con la aprobación de la CDN por parte de la Asamblea General de Naciones Unidas. Los trabajos de su preparación duraron más de diez años y contó con algunos instrumentos previos que sentaron las bases para la propuesta final que derivó en el tratado de derechos humanos más ampliamente aprobado en la historia.

La CDN es el primer código universal de los derechos de los niños y las niñas legalmente obligatorio. Entre sus objetivos está superar la Doctrina de Situaciones Irregulares y adoptar plenamente la de la Protección Integral. A lo largo de sus 54 artículos, la CDN crea un marco inédito de protección integral a favor de las personas menores de 18 años, que obliga a los Estados firmantes a respetar, proteger y garantizar el ejercicio de los derechos civiles y políticos, económicos, sociales, culturales, así como los derechos específicos de ese grupo etáreo. Después de su entrada en vigor, prácticamente todos los Estados del mundo han reconocido a la niñez y a la adolescencia como sujetos de derechos, y han tomado acciones, por lo menos en términos legales, para garantizar el efectivo cumplimiento de los mismos. Así, todos los Estados firmantes 


\section{Principio de Efectividad en las Políticas Públicas referentes a la Protección Integral de la Niñez y Adolescencia en el Ecuador}

Vol. 2, núm. Esp., (2018)

Mariuxi Katherine Mata Echeverria

han debido (re)enmarcar sus legislaciones, incluso crear nuevos códigos de la niñez y adolescencia, con base en los cuatro principios generales que orientan a la Convención: 1.No discriminación (Artículo 2), 2. Interés superior del niño (Artículo 3), 3. Derecho a la vida, a la supervivencia y al desarrollo (Artículo 6), y 4. Derecho a opinar y participar libremente (Artículo 12).

Por otra parte Las Reglas de las Naciones Unidas para la Protección de Menores Privados de Libertad (Reglas de Riyadh, 1990) el cual se basa en establecer normas mínimas aceptadas por las Naciones Unidas para la Protección de los Menores privados de libertad en todas sus formas de manera compatible con los Derechos humanos y libertades fundamentales, y con miras a contrarrestar los efectos perjudiciales de todo tipo de detención y fomentar la integración en la sociedad.

Como resultado de este bagaje de Instrumentos Internacionales, existen y se encuentran vigentes, El Convenio $\mathrm{N}^{\circ} 138$, La recomendación $\mathrm{N}^{\circ} 146$ de la Organización Internacional del Trabajo, y; La Carta de la UNESCO sobre la Educación para todos.

En el siglo XX las políticas públicas se han visto fuertemente influidas por la acción de la Organización Internacional del Trabajo, sobre todo en relación con el trabajo o explotación infantil, y luego por la UNICEF, en torno a la alimentación y la escolarización. Durante las dos primeras décadas del siglo XX se dieron a conocer varias declaraciones sobre los derechos del niño, algunas de ellas producto de motivaciones profundamente literarias, otras de contenidos meramente resolutivos declarados por organizaciones científicas y pedagógicas. 


\section{Principio de Efectividad en las Políticas Públicas referentes a la Protección Integral de la Niñez y Adolescencia en el Ecuador}

Vol. 2, núm. Esp., (2018)

Mariuxi Katherine Mata Echeverria

Además de los Instrumentos Jurídicos referenciados, existen otros que han sido ratificados por el Ecuador, sumado a normativas nacionales que buscan proteger de manera insistente los intereses propios del Sector de la Niñez y Adolescencia, estos, por supuesto tienen influencia positiva de las normativas internacionales que han sido mencionadas.

Emerge entonces el Principio del Interés del niño trata y muestra a este como un sujeto y ya no como un objeto; el principio integral del interés del niño será entonces uno de los principios cardinales en materia de derechos del niño, niña y adolescente, más importantes en materia de niñez y adolescencia, contextualizando la normativa internacional, como sigue en el artículo $1^{\circ}$ de la Convención sobre Derechos del Niño (ONU, 1990), niño es todo ser humano menor de dieciocho años de edad.

Los documentos internacionales que se consideran, expresan, desde el instante mismo en que se adoptan, un acuerdo conjuntado y armónico de diversas ideas nacionales que se concreta como expresión de la voluntad común de los Estados que las aprueban, toda vez que gobiernan con sus disposiciones una esfera mucho más amplia que la de la propia ley interna y evidencian por su misma naturaleza el carácter internacional que conviene con la índole de la materia que regula.

El carácter abstracto y pragmático de estos documentos internacionales exige que el trascender el ámbito nacional mediante el acto formal y posterior de su ratificación por el Estado, que éste les promulgue de modo exacto, claro, preciso y ordenado al igual que el resto de sus leyes internas; pero ha de hacerse constar que aun antes de que se produzca el actor formal de su ratificación, tales declaraciones condicionan en cierta medida la postura del Estado, al impulsarle 


\section{Principio de Efectividad en las Políticas Públicas referentes a la Protección Integral de la Niñez y Adolescencia en el Ecuador}

Vol. 2, núm. Esp., (2018)

Mariuxi Katherine Mata Echeverria

a la realización de las acomodaciones imprescindibles en su legislación, con el fin de armonizar sus normas internas a los presupuestos que la conciencia internacional exija.

\section{La Niñez y Adolescencia en Latinoamérica}

Según datos estadísticos de CEPAL, al 2010 la población latinoamericana menor de 19 años ascendía a 215.640.838 niños y adolescentes, lo cual representa casi el 37\% de la población total de Latinoamérica. De esta cifra se deriva una gran proporción de niños y adolescentes, que han sido víctimas de explotación, violencia, abandono, problemas escolares, alcohol, drogas, entre muchos otros problemas que los oprimen día a día.

En el reporte "Progreso para la Infancia" del año 2009, se visibilizan los obstáculos que se encuentran con respecto a la información disponible acerca de estas problemáticas, "la dificultad para estimar el número de niños y niñas afectados por circunstancias particulares como trabajo infantil; conflictos armados y otras modalidades de violencia; explotación y abuso sexuales; pérdida de la familia; y leyes y procesos judiciales deficientes-no solo refleja las susceptibilidades públicas y políticas alrededor de estos temas, sino también el desconocimiento de los datos que se requieren y la manera más adecuada de reunirlos. Estas graves fallas no han permitido realizar un análisis preciso y efectivo de la situación de la niñez." (UNICEF, 2009).

Rosa Blanco y Mami Humayahara también mencionan el problema de información en la "Síntesis Regional de Indicadores de la Primera Infancia”, citando que "la información sobre los colectivos de niños y niñas que viven en situación de vulnerabilidad es muy escasa. Se dispone de información respecto a los niños y niñas con discapacidad y de diferentes grupos étnicos, recopilada a través del censo de población o de los centros de atención, pero no está desglosada 


\section{Principio de Efectividad en las Políticas Públicas referentes a la Protección Integral de la Niñez y Adolescencia en el Ecuador}

Vol. 2, núm. Esp., (2018)

Mariuxi Katherine Mata Echeverria

por edad. No se cuenta con información sistemática sobre los niños y niñas en otras situaciones

de vulnerabilidad como abandono, maltrato y violencia intrafamiliar, abuso sexual, prostitución infantil o adicción, entre otras. (Blanco \& Humayahara, 2004).

Dentro de este marco se presenta el "Observatorio Juvenil Interactivo de Transformación Social", el cual tiene como objetivo servir de instrumento para el empoderamiento y la integración de las redes juveniles, y ser un mecanismo para potenciar la movilización de estas, gracias a su federación, información y capacitación. El Observatorio será exitoso si contribuye a lograr mayor incidencia a nivel social y político, y convertir a las redes juveniles en agentes de cambio social.

Unido a esto, socializa la información en búsqueda de una retroalimentación que complemente los insumos que genere, como también motivar a la juventud al desarrollo de iniciativas diversas en la búsqueda de soluciones que contribuyan en la generación de cambios, para el disfrute de una mejor calidad de vida.

El proceso que el Observatorio ha seguido para su creación constituye el documento base, y tiene como objetivo ser una investigación teórica, estadística y analítica que describa el estado actual de la niñez en América Latina en función de los indicadores seleccionados. Estos primeros cinco temas prioritarios, según el Observatorio, muestran la realidad que deben enfrentar a diario los niños latinoamericanos, en los diversos espacios dentro de los que se desenvuelven: el hogar, escuela, y comunidad; según el siguiente orden:

1. Maltrato y violencia 


\section{Principio de Efectividad en las Políticas Públicas referentes a la Protección Integral de la Niñez y Adolescencia en el Ecuador}

Vol. 2, núm. Esp., (2018)

Mariuxi Katherine Mata Echeverria

\section{Familias Saludables}

3. Alcoholismo y drogadicción

4. Explotación sexual comercial de menores de edad.

\section{Deserción escolar}

Dicho orden refleja en los primeros lugares (1 y 2 ) las causas, en su mayoría, de los restantes temas $(3,4,5)$, según lo define en forma clara, objetiva y puntual la opinión pública.

No obstante, evidencia además las consecuencias de las familias no saludables en cuanto al trabajo infantil y doméstico, embarazo adolescente, malnutrición y pandillas juveniles al tener una amplia relación. Asimismo, dichos temas van de la mano con la deserción escolar, debido a que por ausencia de los padres de familia o por motivos laborales, divorcio, separación entre cónyuges, hogares donde la madre deba asumir un doble rol (padre y madre), entre otras situaciones, surge la necesidad de definir prioridades para proveer de dinero a la familia y hacer frente a los gastos básicos del hogar, alimentos, servicios públicos, etc., frente a mantener a los hijos/as en el proceso de enseñanza - aprendizaje.

Parte de la realidad de América Latina son los altos índices de Deserción Escolar, a pesar del esfuerzo por incrementar el acceso a la educación, la deserción no se ha logrado eliminar aún, lo cual, afecta directamente al insertarse al mercado laboral, cada vez más competitivo y demandando habilidades y destrezas más técnicas y específicas. 


\section{Principio de Efectividad en las Políticas Públicas referentes a la Protección Integral de la Niñez y Adolescencia en el Ecuador}

Vol. 2, núm. Esp., (2018)

Mariuxi Katherine Mata Echeverria

El indicador explotación sexual comercial de menores de edad, no cuenta con estadísticas

veraces y anuales, debido a la dificultad de cálculo al ser una actividad ilícita, por lo que esta falta de información, entorpece el proceso de establecer una tendencia para los próximos años.

Sin embargo, según algunos datos presentados en diversos estudios citados anteriormente, se estima que existen unos 160.000 niños explotados en Costa Rica y República Dominicana, entre 200.000 y 300.000 en Honduras, Guatemala, el Salvador y Nicaragua, unos 500.000 en Brasil y 40.000 en Venezuela, por lo que los datos a nivel latinoamericano, la cifra asciende a más de un millón de niños víctimas de la explotación sexual comercial.

Según un documento de UNICEF, "Deserción Escolar: Un problema urgente que hay que abordar" para el año 2000 "en promedio, cerca del 37\% (unos 15 millones) de los adolescentes latinoamericanos de entre 15 y 19 años de edad abandonan la escuela a lo largo del ciclo escolar, y casi la mitad de los que desertan lo hacen tempranamente, antes de completar la educación primaria". (PREAL 2003)

Sin embargo, estos datos, cambian de acuerdo a la zona, sea urbana o rural, y al país que se analice, por ejemplo países con un menor desarrollo sobre todo Centroamericanos, son los más tendientes a desarrollar mayores índices de deserción que países del Sur, de la misma forma, el índice es mayor en zonas rurales que urbanas.

Otras variables de influencia son el sexo, escolaridad de los padres, ingreso del hogar, entre otros, teniendo como resultado, mayor deserción de niños que de niñas y una gran desigualdad, al pertenecer la mayor parte de los desertores a hogares de bajos ingresos. 


\section{Principio de Efectividad en las Políticas Públicas referentes a la Protección Integral de la Niñez y Adolescencia en el Ecuador}

Vol. 2, núm. Esp., (2018)

Mariuxi Katherine Mata Echeverria

Este desequilibrio, se explica en el informe "La Juventud en Iberoamérica, Tendencias y

Urgencias" de la CEPAL, para el cual "la deserción según área geográfica presenta una serie de contrastes. La deserción en primaria en el área rural duplica con creces (56\% hombres y 53\% mujeres) la de las zonas urbanas (23\% hombres y $21 \%$ mujeres). En el caso de la enseñanza secundaria, la deserción rural es menor que la anterior, en parte debido a que probablemente quienes logran acceder a las pocas escuelas secundarias cercanas tienen desde ya un mayor compromiso educacional, considerando que la cobertura secundaria es muy inferior en zonas rurales.”(CEPAL, 2007)

En este mismo informe se cita que "la mayoría de los países iberoamericanos enfrenta hoy un problema grave de deserción escolar antes de y durante la educación secundaria. En América Latina y el Caribe, solo la mitad de los estudiantes que se matriculan en la educación primaria terminan dicho ciclo.

Esto afecta específicamente a los jóvenes, pues la continuidad en el nivel secundario coincide con el ingreso al segmento etario juvenil”. (CEPAL, 2007) ibíd.

El documento "Panorámica Regional: América Latina y el Caribe", de UNESCO, menciona que el problema de la deserción se debe atacar desde diversas áreas, ya que "no se tiene mucha conciencia de la magnitud del problema de la deserción escolar. Las características de la deserción escolar varían muy considerablemente de un país a otro. En la República Dominicana, donde la tasa de deserción en el primer grado de primaria es de un $14 \%$, y en Nicaragua, donde esa tasa se eleva a un $18 \%$, los niños tropiezan con grandes problemas para pasar de un grado a otro en sus primeros años de escolarización. En algunos países, como Saint 


\section{Principio de Efectividad en las Políticas Públicas referentes a la Protección Integral de la Niñez y Adolescencia en el Ecuador}

Vol. 2, núm. Esp., (2018)

Mariuxi Katherine Mata Echeverria

Kitts y Nevis o Suriname, se registran tasas altas de deserción escolar en el último grado de primaria, lo que refleja en parte las deficiencias del sistema de exámenes escolares. Los datos y elementos de información procedentes de numerosos países de la región muestran también que el riesgo de desertar la escuela primaria aumenta con la edad, aunque el grado de intensidad de la relación entre esos dos factores sea variable". (UNESCO, 2011)

El "Panorama Educativo 2010: Desafíos Pendientes" por su parte, menciona que "para el grupo más joven (15-19 años), 7 de 23 países poseen una tasa de conclusión por sobre el 95\%. Estos son Bahamas, Chile, Argentina, Barbados, Uruguay, Dominica y México.” (UNESCO, 2011)

Estos datos revelan los contrastes que existen en materia de educación, desde desigualdad de género, disparidad en ingresos y desigualdad de acceso en zonas rurales, dentro de los cuales, los sectores más pobres son los más afectados, alimentando el círculo de la pobreza, ya que según estudios, se determina que "a mayor nivel de educación, mayor nivel de ingresos percibidos."(CEPAL, 2007)

El documento de CEPAL antes citado, menciona que el 80\% de los jóvenes provenientes de zonas urbanas, son miembros de hogares con "capital educativo insuficiente" por parte de sus padres y "entre un $60 \%$ y un $80 \%$ de ellos no alcanza el umbral educativo básico para acceder al bienestar".

Junto a este panorama, las políticas educativas tienen otros desafíos que enfrentar, como lo es la sociedad del conocimiento, con retos específicos en acceso a tecnología, equidad en oportunidades y calidad en Latinoamérica. 


\section{Principio de Efectividad en las Políticas Públicas referentes a la Protección Integral de la Niñez y Adolescencia en el Ecuador}

Vol. 2, núm. Esp., (2018)

Mariuxi Katherine Mata Echeverria

Aun cuando es un avance fundamental haber logrado que cerca del $90 \%$ de los niños y niñas de 5 años se encuentren en el sistema educativo, los aportes de investigación cognitiva muestran básicamente que son los tres primeros años de vida de la infancia los que marcan su desarrollo cerebral que permitirán trascender sobre los comportamientos y aprendizajes futuros (Peralta Espinosa, 2009). De esta forma si observamos lo que sucede, en el país, con la educación de la población en sus primeros años se detecta, en general, una exclusión: pues no se ejerce, ni se garantiza el derecho a la educación oportuna y pertinente desde el nacimiento. En este sentido, las coberturas desde las distintas propuestas de educación inicial durante los tres primeros años de vida son muy bajas: ocho de cada 10 niños y niñas no recibe ningún tipo de educación dentro de los programas formales o no formales. En el campo y la ciudad las tendencias son similares, aunque la niñez rural recibe mayor atención. Así, mientras en las ciudades el $84 \%$ de la infancia menor de cuatro años no accede a ningún programa, en el campo el porcentaje es del 77\%, pues es donde la mayor parte de programas vinculados a los temas del cuidado y desarrollo infantil se ha concentrado.

En las recomendaciones del Comité de Derechos del Niño al Ecuador en el 2012, se destacan los avances en materia de cobertura educativa y la eliminación de las diferencias en el acceso a la educación entre niños y niñas. Pero también se llama la atención sobre el abandono de la escuela sobre todo entre la población indígena, así como la alta tasa de abusos y hostigamiento sexuales contra las niñas y la persistencia de castigos corporales como forma de “disciplina” en las escuelas. El Comité también señala con preocupación que la más baja tasa de terminación de los estudios secundarios se registra entre los niños indígenas y las adolescentes embarazadas, lo que indica una deficiencia en la calidad de la educación. Por último, otro 


\section{Principio de Efectividad en las Políticas Públicas referentes a la Protección Integral de la Niñez y Adolescencia en el Ecuador}

Vol. 2, núm. Esp., (2018)

Mariuxi Katherine Mata Echeverria

motivo de preocupación destacado por el Comité es que los hijos de los trabajadores migrantes en situación irregular no tengan acceso al sistema de enseñanza (Comité de Derechos del Niño, 2010).

Aunque el Comité es consciente de los logros del Estado Parte en la esfera de la educación, sigue preocupado por la alta tasa de abandono escolar entre la escuela primaria y la secundaria y por la alta tasa de repetición a ambos niveles, por las disparidades entre los sexos en los ingresos en la escuela secundaria y por las disparidades en el acceso a la educación entre las zonas rurales y las urbanas. El Comité recomienda al Estado Parte que refuerce sus sistemas y sus políticas educativas a fin de reducir las disparidades entre los sexos y entre las distintas zonas geográficas y de establecer programas de retención y de formación profesional para jóvenes que hayan abandonado la escuela. Aunque el Comité es consciente de que en la reforma de los programas de estudios de enseñanza primaria se han incluido medidas para el ejercicio de los derechos del niño al esparcimiento y a las actividades recreativas y culturales, sigue preocupado por la insuficiencia de esas medidas, en particular para los niños que viven en las zonas urbanas pobres o en las zonas rurales. A la luz del artículo 31 de la Convención, el Comité recomienda al Estado Parte que fortalezca sus medidas para mejorar el acceso de los niños al esparcimiento y a las actividades recreativas y culturales, especialmente los grupos de niños más vulnerables.

\section{Tutela Jurídica para la Protección de la Niñez y Adolescencia en el Ecuador}

El desarrollo de la Tutela Jurídica de los Derechos de la Niñez y Adolescencia en una sociedad se distinguen claramente en las competencias de las políticas sociales, planteando la 


\section{Principio de Efectividad en las Políticas Públicas referentes a la Protección Integral de la Niñez y Adolescencia en el Ecuador}

Vol. 2, núm. Esp., (2018)

Mariuxi Katherine Mata Echeverria

defensa y el reconocimiento de los Derechos de los Niños y los jóvenes como una cuestión que depende de un adecuado desarrollo de las políticas sociales de cada nación.

Las políticas se caracterizan por estar diseñadas e implementadas por la sociedad civil y el Estado, por estar descentralizadas y focalizadas en los gobiernos seccionales, municipales o distritales, según la denominación de cada país.

Se abandona la noción de menores como sujetos definidos de manera negativa, por lo que no tienen, no saben o no son capaces, y pasan a ser definidos de manera afirmativa, como sujetos plenos de Derecho tal como lo menciona la evolución de los Derechos de la niñez y adolescencia, haciendo hincapié en la necesidad de darles a los niños y adolescentes el lugar de personas que requieren para ejercer sus derechos y cumplir sus obligaciones.

La protección es de los Derechos del niño y/o el adolescente. No se trata como en el modelo anterior de proteger a la persona del niño o adolescente, del "menor", sino de garantizar los Derechos de todos los Niños y Adolescentes. Por lo tanto, esa protección reconoce y promueve Derechos, no los viola ni restringe.

También deberían articularse tanto el sistema judicial como los órganos en los cuales se formula y se vigila el cumplimiento de la política de la niñez y de la adolescencia -que en este caso son los Consejos Cantonales de la Niñez y las Juntas Protectoras de Derechos-, y los que realizan la prevención, atención y la restitución de derechos -que en Ecuador son los Centros de Protección de Derechos-. Como se constata, el Sistema de Protección idealmente estaría compuesto por varias instancias estatales que tendrían que trabajar de manera coordinada a nivel local, provincial y nacional. 


\section{Principio de Efectividad en las Políticas Públicas referentes a la Protección Integral de la Niñez y Adolescencia en el Ecuador}

Vol. 2, núm. Esp., (2018)

Mariuxi Katherine Mata Echeverria

También por ese motivo la protección no puede significar intervención estatal coactiva, la idea debe conjugar las dos partes el Estado y la Sociedad, encaminarse juntos a lograr esa meta la protección integral de la Niñez y Adolescencia. De otro lado la idea de universalidad de los Derechos, se desprende que estas leyes son para toda la infancia y Adolescencia, no para una parte.

Por eso se les reconocen todos los Derechos que tienen todas las personas, más un plus de Derechos específicos precisamente por reconocerse el hecho de que están creciendo. De ahí que de todos los Derechos, uno que estructura la lógica de la protección integral sea el Derecho del niño a ser oído y a que sus opiniones sean tenidas en cuenta. Se jerarquiza la función del juez en tanto éste debe ocuparse de cuestiones de naturaleza jurisdiccional, sean de Derecho público (penal) o privado (familia). El juez, como cualquier juez, está limitado en su intervención por las garantías.

En cuanto a la política criminal, se reconocen a los Niños todas las garantías que les corresponden a los adultos en los juicios criminales según las constituciones nacionales y los instrumentos Internacionales pertinentes, más garantías específicas. La principal, en relación con los Adolescentes, es la de ser juzgado por tribunales específicos con procedimientos específicos, y la de que la responsabilidad del adolescente por el acto cometido se exprese en consecuencias jurídicas absolutamente diferentes de las que se aplican en el sistema de adultos. Este reconocimiento de garantías es independiente del hecho de sostener que los Niños y jóvenes son inimputables, como es el caso, por ejemplo, del Estatuto del Niño y del Adolescente de Brasil. 


\section{Principio de Efectividad en las Políticas Públicas referentes a la Protección Integral de la Niñez y Adolescencia en el Ecuador}

Vol. 2, núm. Esp., (2018)

Mariuxi Katherine Mata Echeverria

Se establece como consecuencia jurídica de la comisión de un delito por parte de un joven un catálogo de medidas, en el que lo alternativo, excepcional, ultima ratio y por tiempo breve es la privación de libertad. Estas medidas se extienden desde la advertencia y la amonestación hasta los regímenes de semilibertad o privación de la libertad en institución especializada. Deben dictarse por tiempo determinado. Se determina que la privación de libertad será una medida de último recurso, que deberá aplicarse por el tiempo más breve que proceda y, en todos los casos, por tiempo determinado como consecuencia de la comisión de un delito grave.

Todos estos Derechos de la Niñez y Adolescencia, tiene implícito su deber ser, deber ser que tiene como garante al Estado, pero el Estado, sólo no puede brindar ese seguro que necesita este sector de nuestra sociedad.

El nuevo Sistema Descentralizado, del Ecuador, de Protección Integral de la Niñez y Adolescencia busca recuperar la universalidad de la categoría infancia, perdida con las primeras leyes para "menores". Ya no se trata de incapaces, medias-personas o personas incompletas, sino de personas completas cuya única particularidad es que están creciendo.

Este Sistema Nacional Descentralizado para la protección integral de los Niños, Niñas y Adolescentes. El mismo que reza dentro de la carta magna y del Código Orgánico de la Niñez y Adolescencia en su parte pertinente, evidencia toda una estructura que existe en el Ecuador donde éste se encuentra representado por un Consejo Nacional de la Protección Integral de la Niñez y Adolescencia. El Organismo que en este caso funcionaría para el verdadero cuidado de nuestros Niños, Niñas y Adolescentes son las Juntas Cantonales, que son instituciones 


\section{Principio de Efectividad en las Políticas Públicas referentes a la Protección Integral de la Niñez y Adolescencia en el Ecuador}

Vol. 2, núm. Esp., (2018)

Mariuxi Katherine Mata Echeverria

seccionales creadas por los municipios.Según el artículo 207 ibídem, las Juntas Cantonales de Protección de Derechos se integrarán con tres miembros principales y sus respectivos suplentes, los que serán elegidos por el Concejo Cantonal de la Niñez y Adolescencia de entre candidatos que acrediten formación técnica necesaria para cumplir con las responsabilidades propias del cargo, propuestos por la sociedad civil. Durarán tres años en sus funciones y podrán ser reelegidos por una sola vez.

La separación del Estado - Sociedad comienza justamente en este postulado, pues las Juntas Cantonales en el Ecuador no están conformadas por personal esencialmente idóneo. Lo que le merma el resultado al Sistema, esto hace que el objetivo trazado por el Estado como finalidad brindar la protección integral de los Derechos de la Niñez y Adolescencia, no se concrete.

El límite del cumplimiento de los derechos de la niñez y de la adolescencia es el de la ciudadanía social de sus padres, madres y familias. Aun cuando existiese un sistema de protección de la niñez y adolescencia, éste, en sí mismo, no sería capaz de crear las condiciones necesarias para garantizar los derechos universales. Esto se debe a que mientras no esté garantizada la protección social para toda la población, no será posible sólo generarla para la infancia. Si la niñez y la adolescencia son una categoría histórica, entonces, es fundamental el poder configurador del Estado y su institucionalidad como garante de una política pública respecto a los derechos de este grupo social. Sin embargo, y en ello se ha de insistir, la protección social de la población -incluyendo a la infancia- sólo puede garantizarse si la desigualdad e inequidad, intrínseca a una sociedad de clases, es resuelta. De ahí que la 


\section{Principio de Efectividad en las Políticas Públicas referentes a la Protección Integral de la Niñez y Adolescencia en el Ecuador}

Vol. 2, núm. Esp., (2018)

Mariuxi Katherine Mata Echeverria

redistribución de los ingresos y de la riqueza sean condiciones innegociables para la puesta en macha y garantía de cualquier sistema de protección con enfoque de derechos.

\section{La protección integral de los niños, niñas y adolescentes dentro de la Legislación}

\section{Ecuatoriana}

La Constitución de 2008, en su artículo 341, establece la existencia del Sistema Nacional Descentralizado de Protección Integral de la Niñez y Adolescencia -SNDPINA-. Este artículo dispone con absoluta claridad que el Sistema Nacional Descentralizado de Protección Integral de la Niñez y la Adolescencia será el encargado de asegurar el ejercicio de los derechos de niñas, niños y adolescentes, visibilizándolo como parte de los sistemas especializados a través de los cuales se asegura la protección integral a la población, los mismos que están regulados en el marco del Sistema Nacional de Inclusión y Equidad Social. Esta Constitución contiene, además, varios mandatos relacionados con los derechos de la niñez y adolescencia. Lo más grave del periodo 2010 -2015 es el desconocimiento que las autoridades legislativas, administrativas y judiciales han hecho de estos principios y normas y la interpretación arbitraria de éstas.

La Ley Orgánica de Consejos Nacionales para la Igualdad -LOCNI- crea, entre otros, el Consejo Nacional de la Igualdad Intergeneracional -CNII-, en donde desaparecen las características de especificidad y especialidad del SNDPINA. También se elimina el carácter descentralizado de este sistema al suprimir los Consejos Cantonales de la Niñez y Adolescencia - CCNA-, transformándolos en Consejos Cantonales de Protección de Derechos -CCPD-, en donde no se aprecia, más bien se ignora, la prioridad absoluta que debe asignarse a la niñez y adolescencia en la ejecución de políticas públicas y en la provisión de recursos. 


\section{Principio de Efectividad en las Políticas Públicas referentes a la Protección Integral de la Niñez y Adolescencia en el Ecuador}

Vol. 2, núm. Esp., (2018)

Mariuxi Katherine Mata Echeverria

Esta ley asigna a los consejos nacionales para la igualdad -CNI-, atribuciones de: formulación, transversalización, observancia, seguimiento y evaluación de las políticas públicas relacionadas con temáticas específicas, entre ellas la generacional, sin embargo no hace referencia a la responsabilidad de establecer políticas públicas específicas relativas a los derechos de la niñez y adolescencia. En relación a la política pública, la rectoría de éstas, se concentra en el nivel central de gobierno siendo los ministerios los que la ejercen (artículo 154 de la Constitución). No define atribuciones de política pública a los gobiernos autónomos descentralizados -GAD-, ni la obligación de destinar recursos preferentes para servicios y programas, como sí lo hacía la Constitución en el año 1998. No establece responsabilidades en materia de protección de derechos a la niñez y adolescencia, por lo que la rectoría de la política está atribuida de manera dispersa. Si bien define la obligatoriedad de la coordinación interinstitucional, la cual también es una obligación de los CNI, cabe señalar que estos consejos deben coordinar con los ministerios las temáticas constitucionales: género, generacional, étnico, movilidad y discapacidad, las cuales invisibilizan a los sujetos y titulares de derechos.

En relación con la preocupación que manifiesta el Comité, en el párrafo 13 de sus Observaciones al Informe Oficial de 2010, relacionadas con la carencia de coordinación entre el nivel central y los CCNA y las Juntas Cantonales de Protección de Derechos -JCPD-, debemos informar que la mencionada LOCNI, no contempla esta obligación de los gobiernos locales y concentra la rectoría de la política pública en los Ministerios, afianzando con esto un modelo ultra centralista que de ninguna manera favorece ni facilita la construcción de sistemas locales de protección. Por otro lado, a nivel local se han aprobado ordenanzas para la estructuración de los CCPD las cuales presentan serios problemas de orden técnico en su formulación, reflejan graves 


\section{Principio de Efectividad en las Políticas Públicas referentes a la Protección Integral de la Niñez y Adolescencia en el Ecuador}

Vol. 2, núm. Esp., (2018)

Mariuxi Katherine Mata Echeverria

contradicciones e incoherencias relacionadas con las competencias, estructura, financiamiento, participación social, entre otras. De otro lado, los CCPD están profundamente limitados por las capacidades propias de los municipios, puesto que en los municipios pequeños, que son la mayoría del país, estos se ven escasos de recursos para su estructuración. Las reformas implementadas a través de la LOCNI han desatado una modificación profunda de la normativa que impulsó los sistemas cantonales de niñez y adolescencia y consecuentemente tienen un impacto sobre las JCPD. Esto ha creado gran preocupación a nivel local ante la posibilidad de que colapsen las JCPD al transformarlas en instancias de protección de derechos de todas las personas - niños, niñas y adolescentes, jóvenes, mujeres, pueblos y nacionalidades, indígenas, adultos mayores, personas en movilidad humana, personas privadas de la libertad, entre otras-, con el mismo personal y capacidad administrativa. Hasta el año pasado, solo con niñez y adolescencia, las JCPD ya sufrían un represamiento de casos muy alto. La nueva normativa está orientada a eliminar el sistema local especializado en niñez y adolescencia transformándolo en un sistema de protección de derechos de todas las personas. Las reformas implementadas a través de la LOCNI han desatado una modificación profunda de la normativa que impulsó los sistemas cantonales de niñez y adolescencia y consecuentemente tienen un impacto sobre las JCPD.

Por otro lado, las políticas de protección integral, no se reflejan ni en el Plan Nacional del Buen Vivir -PNBV ni en la planificación de los gobiernos autónomos descentralizados. Estos planes, fueron sustituidos de forma tácita por las agendas para la igualdad, a través de la LOCNI. Conforme su artículo 13, las agendas contienen las "propuestas de políticas públicas de cada Consejo Nacional para la Igualdad", las cuales deben ser discutidas, consensuadas y articuladas con las políticas sectoriales para su ejecución por parte de los ministerios. La LOCNI, dispone, 


\section{Principio de Efectividad en las Políticas Públicas referentes a la Protección Integral de la Niñez y Adolescencia en el Ecuador}

Vol. 2, núm. Esp., (2018)

Mariuxi Katherine Mata Echeverria

en contraposición con lo establecido en la Constitución, la formulación de la Agenda de Igualdad Intergeneracional, en lugar de generacional.

La creación de un control comunitario respecto a las instituciones que forman parte del sistema nacional descentralizado de la Niñez y Adolescencia, y de mecanismos que dinamicen la ejecución de los planes y programas de protección de los Derechos humanos de la Niñez y Adolescencia para el desarrollo integral de los mismos, sería la meta idónea para enrumbar el nexo del Estado y la Sociedad, no solo en el Ecuador sino en Latinoamérica a la luz de los convenios Internacionales y los encuentros, conversatorios que se hacen al respecto, con especial direccionamiento al Interés Superior del Niño, focalizando, particularmente en el Ecuador la ausencia de este Interés Superior incluso en la lírica jurídica que establece la propia Constitución ecuatoriana.

La protección integral como principio fundamental del cuidado de niñez y adolescencia en Situación Irregular

\section{La Doctrina de La Situación Irregular de la Niñez y Adolescencia}

En términos teóricos, se ha sostenido que las leyes que regulaban la situación de la infancia y la juventud con anterioridad a la Convención Internacional pertenecen a lo que se ha dado en llamar la "doctrina de la situación irregular". Estas leyes conciben a los niños y a los jóvenes como objetos de protección a partir de una definición negativa de estos actores sociales, en palabras de Antonio Carlos Gomes da Costa, una definición basada en lo que no saben, no tienen o no son capaces. 


\section{Principio de Efectividad en las Políticas Públicas referentes a la Protección Integral de la Niñez y Adolescencia en el Ecuador}

Vol. 2, núm. Esp., (2018)

Mariuxi Katherine Mata Echeverria

En líneas generales, el sistema de la situación irregular puede ser caracterizado mediante las siguientes nociones:

La primera es que refleja criterios criminológicos propios del positivismo de fines del siglo pasado y principios de éste. De esa concepción positivista se deriva un sistema de justicia de menores que justifica las reacciones estatales coactivas frente a infractores (o "potenciales infractores") de la ley penal a partir de las ideas del tratamiento, la resocialización -o neutralización en su caso- y, finalmente, de la defensa de la sociedad frente a los peligrosos. Desde la perspectiva de las teorías del castigo, tal justificación ha sido llamada prevención especial y dio paso al reemplazo de las penas por medidas de seguridad, terapéuticas o tutelares respecto de estos "menores en situación irregular" o en "estado de abandono, riesgo o peligro moral o material", o en las igualmente vagas -no obstante ser más modernas- categorías de "menores en circunstancias especialmente difíciles" o "en situación de disfunción familiar".

El segundo rasgo característico de la situación irregular es el argumento de la tutela. Mediante este argumento fue posible obviar dos cuestiones centrales en materia políticocriminal. En primer lugar, el hecho de que todos los derechos fundamentales de los que gozan los adultos no fueran reconocidos a los niños y a los jóvenes. En segundo lugar, el hecho de que las consecuencias reales de esa forma de concebir y tratar a la infancia y la juventud sólo reprodujera y ampliara la violencia y marginalidad que se pretendía evitar con la intervención "protectora" del Estado.

El tercer rasgo característico de estas leyes es la singular función atribuida al juez de menores, quien deja de cumplir funciones de naturaleza jurisdiccional para cumplir 


\section{Principio de Efectividad en las Políticas Públicas referentes a la Protección Integral de la Niñez y Adolescencia en el Ecuador}

Vol. 2, núm. Esp., (2018)

Mariuxi Katherine Mata Echeverria

funciones más propias de las políticas sociales, por decirlo de alguna manera. En este sentido, es importante recordar que el mayor porcentaje del trabajo de los juzgados de menores que funcionan según las previsiones de las leyes de la situación irregular es de naturaleza tutelar o asistencial. Esta función del juez de menores y, en general, la lógica de la situación irregular tuvo gran acogida en América Latina y se articuló perfectamente con los sistemas procesales inquisitivos de la región. Más aún, sistemas inquisitivos y sistemas de menores basados en el sistema de la situación irregular se han alimentado recíprocamente en América Latina en los últimos ochenta años.

La Convención Sobre los Derechos del Niño, aprobada por la Asamblea General de las Naciones Unidas, el 20 de noviembre de 1989, luego de diez años de intenso trabajo por parte de la comunidad Internacional, constituye para los pueblos y gobiernos del mundo un reto jurídicosocial de relevancia universal, por cuanto comprende un tratado Internacional de Derechos humanos, que cambia radicalmente el rumbo doctrinado seguido por las legislaciones respecto de la Niñez y la Adolescencia.

Treinta años antes de su promulgación, el 20 de noviembre de 1959, se proclamó la Declaración de Derechos del Niño, que no bastó para hacer cesar el tratamiento segregacionista de la infancia, por efecto de la aplicación de la normativa de la Situación Irregular. No bastó, entre otras cosas, porque, en estricto Derecho Internacional, las declaraciones son una simple formulación de Derechos, que reconocen éticamente situaciones de Derecho, pero que no son de obligatorio cumplimiento por los Estados parte de esa manifestación de intenciones, muchas 


\section{Principio de Efectividad en las Políticas Públicas referentes a la Protección Integral de la Niñez y Adolescencia en el Ecuador}

Vol. 2, núm. Esp., (2018)

Mariuxi Katherine Mata Echeverria

veces más románticas o reflejo de un momento político, que una verdadera intención o voluntarismo de Estado.

Es decir, que al no tener carácter imperativo, las declaraciones se hacen, por lo general, ineficaces dentro de los países que la suscriben, convirtiéndose en una especie de "invitación" a comportarse de una manera determinada literalmente eso, una feliz invitación, por cuanto carece de mecanismos para dar eficacia y generar efectos de los Derechos declarados. Se hace esta afirmación, con la intención de no dejar duda alguna sobre la importancia de la proclamación de un Instrumento de imperativo cumplimiento, como la Convención Sobre los Derechos del Niño. Es necesario también afirmar que otros instrumentos, que aunque tampoco sean de obligatorio cumplimiento, por su carácter de Resoluciones de Naciones Unidas, configuran antecedentes de la propia Convención y suministros doctrinario para el diseño de la misma, tanto así que son expresamente citados en su Preámbulo y considerados en sus normas.

Estos Instrumentos son: La Declaración sobre La Protección de la Mujer y el Niño en Estados de Emergencia o de Conflicto Armado, decidida en el año 1974; Las Reglas de las Naciones Unidas para la Administración de Justicia de Menores o reglas de Beijing del año 1985, y La Declaración sobre Principios Sociales y Jurídicos relativos a la Protección y el Bienestar de los Niños con particular referencia a la Adopción y a la Colocación en los Hogares de Guarda, que son de 1986.

Necesario es reiterar que antes de la promulgación de la Convención sobre los Derechos del Niño, prevalecía la consideración minorista del niño como la más clara y deleznable expresión de la Doctrina de La Situación Irregular, en la que se sustenta el paradigma tutelar, con 


\section{Principio de Efectividad en las Políticas Públicas referentes a la Protección Integral de la Niñez y Adolescencia en el Ecuador}

Vol. 2, núm. Esp., (2018)

Mariuxi Katherine Mata Echeverria

un enfoque de la infancia bajo la percepción de lástima, compasión, caridad y represión Repetimos que este paradigma tutelar divide a la infancia entre quienes tienen y pueden y los que no, sometiéndonos a un tratamiento diferencial, sujetos a la "beneficencia" protectora, los excluidos de oportunidades sociales, con una progresiva imposición de reglas que criminalizan su situación de pobreza, tomando como objeto de Derecho las diversas situaciones de hecho adversas, para responder con una especie de marcaje jurídico a la apropiación del ser, desmoronando su condición humana, al someterse a la institucionalización. Serán pues los confinados de la sociedad todos aquellos Niños que al presentar ciertas características (que más bien condiciones), sociales se les tutelará con la represión judicial e institucional.

En el Ecuador se previene este estado de Situación Irregular en el Artículo 35 de la Constitución de la República del Ecuador en donde incluso se menciona la doble vulnerabilidad de las personas que además de cumplir con la vulnerabilidad natural adquieren la que denota la Situación Irregular que es la Situación de Riesgo de un grupo ya vulnerable.

\section{La protección integral como nuevo referente para las relaciones sociales con la niñez y adolescencia}

Los acuerdos Internacionales han insistido desde el siglo anterior en la protección a la niñez y adolescencia, los doctrinarios en la evolución de la determinación en la importancia del cuidado desde su nacimiento al niño, incluso desde su concepción.

La Constitución de la República del Ecuador ha brindado con asentado énfasis la protección integral como principio Rector para el cuidado de la niñez y adolescencia, ésta se ha nutrido de los acuerdos Internacionales, propiamente siendo parte de todos o de algunos de ellos. 


\section{Principio de Efectividad en las Políticas Públicas referentes a la Protección Integral de la Niñez y Adolescencia en el Ecuador}

Vol. 2, núm. Esp., (2018)

Mariuxi Katherine Mata Echeverria

En el Ecuador existe una nueva ley que da como resultado la ausencia de la expresión "Protección Integral para la niñez y adolescencia" reemplazándola por "Protección Integral de Derechos...”

Se presenta entonces una Acción a la que seguramente las políticas públicas pretendieron implementarla por ser positiva, afirmativa, pero al suprimir en su titulado "Niñez y Adolescencia”, ¿acaso no pierde su verdadera razón de ser...? y esa Acción Afirmativa entonces no fue encaminada a la niñez y adolescencia como pretende sugerir el contenido de la nueva Ley Orgánica de los Consejos Nacionales para la Igualdad.

La nueva Ley derogó en su totalidad todo el articulado desde el 190 del Código Orgánico de la Niñez y Adolescencia, referente al Sistema Nacional de Protección Integral para la Niñez y Adolescencia y todos sus organismos, dejando ver que es Estado se encuentra totalmente ajeno a la realidad que viven nuestros niños y adolescentes en la actualidad.

La Situación de riesgo en Latinoamérica de la niñez y Adolescencia es evidente y eminente, más aún cuando la Familia, La Sociedad y el Estado están indiferentes ante su responsabilidad sobre el cuidado que les compete en los actuales momentos históricos de carencia de protección que vive este grupo ahora declaradamente olvidado e incluso acuñado con otros sectores que sin dejar a un lado su necesidad son el resultado del deterioro de la niñez y adolescencia.

Se pretende que el presente trabajo brindar la apertura al debate, y mostrar la necesidad imperiosa de nuestros niños y adolescentes, que el Estado asuma su responsabilidad 


\section{Principio de Efectividad en las Políticas Públicas referentes a la Protección Integral de la Niñez y Adolescencia en el Ecuador}

Vol. 2, núm. Esp., (2018)

Mariuxi Katherine Mata Echeverria

implementando políticas públicas y de carácter urgente y humano declare en emergencia al Sector de la niñez y adolescencia.

Que la responsabilidad que tienen las familias, deben ser observadas por una Institución que se debe crear para salvaguardar la protección de los niños y adolescentes.

Que la sociedad asuma su deuda social con nuestros niños y adolescentes y no seamos simples espectadores de lo que vemos en nuestro alrededor, permaneciendo incólume nuestro deseo vivo de cuidar a los nuestros no podemos cerrar los ojos ante los ajenos, porque mañana lo harán con los nuestros y de la misma manera.

Latinoamérica necesita mano firme a las Acciones Afirmativas cuidar finamente que no se disgreguen, el Ejecutivo deberá tomar cartas vigilando la función de los Alcaldes y Prefectos, quienes deberían ser los principales guardianes de la protección de la niñez y adolescencia, como gobiernos seccionales.

Garantizar el cumplimiento de los derechos del niño y adolescente es una responsabilidad del Estado, que debe mediante Acciones Afirmativas aportar a la consecución del cumplimiento de sus derechos; el incumplimiento por parte del Estado no es otra cosa que el incumplimiento del pacto social del que hablaba Rouesseau, olvidar la situación de riesgo en la que se encuentran nuestros niños y adolescentes, es más inhumano que la propia realidad que viven éstos.

La situación que vive nuestros Niños y Adolescentes en el Latinoamérica y el mundo, está en la oposición de los que los Acuerdos Internacionales determinan, de los cuales ya hemos mencionado somos parte. 


\section{Principio de Efectividad en las Políticas Públicas referentes a la Protección Integral de la Niñez y Adolescencia en el Ecuador}

Vol. 2, núm. Esp., (2018)

Mariuxi Katherine Mata Echeverria

Nos encontramos en consecuencia, ante una antijuricidad que requiere la imposición de una medida correctiva, El Estado no puede ni debe separarse de la sociedad, ambos mantienen una responsabilidad latente con la Niñez y Adolescencia, entonces ambos deben trabajar por el desarrollo de éstos.

Encarar los programas protectores de conformidad a los principios del interés superior del Niño, en armonía con el Estado la consecución y realización de las políticas públicas será un verdadero éxito y estimar, además que los menores, sin excepción alguna, se encuentran genéricamente tutelados por el Estado.

En la actualidad en el Ecuador, la separación Estado-Sociedad, en Latinoamérica, hace un llamado especial a aquellos que forman parte de los gobiernos de turno, siendo estos los responsables éticos, políticos y sociales del avance o retroceso del desarrollo de la niñez y adolescencia.

\section{La Protección Integral desde una perspectiva doctrinal}

TEJEIRO, (1998), ha dicho que al interior del concepto de protección "se encuentra la búsqueda de la proyección general del niño y el adolescente como entes éticos, el desarrollo de su misma personalidad en términos de sus potencialidades".

La definición de éste autor está dirigida, sin duda, al objeto final de la protección como acción dirigida a un grupo social determinado. Interesaría además, formular una definición de protección integral a Niños y Adolescentes que entrañe las funciones y acciones intrínsecas de su prosecución socio-jurídica. 


\section{Principio de Efectividad en las Políticas Públicas referentes a la Protección Integral de la Niñez y Adolescencia en el Ecuador}

Vol. 2, núm. Esp., (2018)

Mariuxi Katherine Mata Echeverria

Hecha esta breve consideración, nos aproximarnos a la definición de Protección Integral al considerarla como el conjunto de acciones, políticas, planes y Programas que con Prioridad Absoluta se dictan y ejecutan desde el Estado, con la firme participación y solidaridad de la Familia y la sociedad para garantizar que todos los Niños y Niñas gocen de manera efectiva y sin discriminación de los Derechos humanos a la Supervivencia, al Desarrollo y a la Participación, al tiempo que atienda las situaciones especiales en que se encuentran los Niños individualmente considerados o determinado grupo de Niños que han sido vulnerados en sus Derechos.

Esta aproximación nos permite ubicar las claras diferencias que existen entre las políticas públicas universales destinadas a generar condiciones sociales, económicas, culturales y de otra índole para la satisfacción de los Derechos colectivos y difusos de todos los Niños, Niñas y Adolescentes, con las políticas especiales destinadas básicamente a atender determinadas circunstancias que provocan situaciones de vulnerabilidad a grupos también determinados de Niños, Niñas y Adolescentes. Las Primeras provocan y generan disfrute Universal de Derechos, las segundas protegen frente a violaciones de estos, para liberar de afecciones sociales o de otra índole a los Niños Para una rápida ubicación histórico-social, podemos decir que la Protección Integral se ha ido armando en la historia del tratamiento a la infancia como una especie de rompecabezas complejo. Ha tenido que pasar un tiempo considerable para que, a través de la crítica a las viejas formas de atención a la Infancia, se haya construido y se continúe construyendo la filosofía social de la protección Integral.

Dogmáticamente, la trilogía Supervivencia, Desarrollo y participación reconoce condiciones subjetivas de derecho a todos los niños y niñas (Ejemplo, la vida, la familia, la 


\section{Principio de Efectividad en las Políticas Públicas referentes a la Protección Integral de la Niñez y Adolescencia en el Ecuador}

Vol. 2, núm. Esp., (2018)

Mariuxi Katherine Mata Echeverria

educación, la nutrición, etc.) que en el deber ser existen de pleno derecho; mientras que en el derecho de protección especial se trata de la presencia de diversas situaciones objetivas y de hecho que perjudican el goce y disfrute real de determinados derechos por parte de un niño o niña en una situación concreta (sean de Supervivencia, desarrollo o participación, o de unos y otros). Por ello se afirma que estos últimos son formulaciones plurales de derechos subjetivos (por ejemplo, todos los niños tienen derecho a la vida), mientras que la protección especial es una formulación singular de hecho o de diversos hechos que determinan un solo derecho, cual es el de estar protegido eficazmente contra estas situaciones, procurar y atender su inmediata restitución a nivel de goce efectivo del derecho violentado.

Para Yuri Emilio Buaiz la Protección Integral es: El conjunto de acciones, políticas, planes y programas que con prioridad absoluta, se dictan y ejecutan desde el estado, con la participación y solidaridad de la familia y la sociedad, para garantizar que todos los niños y niñas gocen, de manera efectiva y sin discriminación, de los Derechos Humanos a la supervivencia, al desarrollo y a la participación.

El criterio de la integralidad está considerado como esencial en el diseño de toda norma de protección de los derechos de la niñez y adolescencia, ya que su materialización exige garantizar todos los derechos a todas las niñas, niños y adolescentes, sin discriminación alguna y no sólo a los que se consideran en situación de riesgo social o peligro.

\section{La Protección Integral desde una perspectiva Constitucional}

La Protección Integral en el marco constitucional, denota una perspectiva de jerarquía respecto a su esencia desde su carácter normativo, los derechos como límites y objetivos del 


\section{Principio de Efectividad en las Políticas Públicas referentes a la Protección Integral de la Niñez y Adolescencia en el Ecuador}

Vol. 2, núm. Esp., (2018)

Mariuxi Katherine Mata Echeverria

poder, el tratamiento constitucional a los derechos y la separación existente entre derechos y garantías se torna en un tema que condiciona el análisis de los mecanismos de aplicación de esta garantía que establece la Norma Suprema.

Por consiguiente el texto constitucional ecuatoriano dice reconocer, valorar y proteger la existencia de una sociedad pluralista, es decir, marcada "por la presencia de una diversidad de grupos sociales, con intereses, ideologías y proyectos diferentes, pero sin que ninguno tenga fuerza suficiente para hacerse exclusivo o dominante" o teniendo la fuerza para ello, esto se encuentra limitado por la "fuerza" de la Constitución, sus garantías y el establecimiento de ese pluralismo como una condición esencial en una democracia sustancial.

Esto a partir de la definición del Ecuador como un "Estado constitucional" -que se dice implica una transformación y no sólo una evolución del "Estado de derecho legislativo"

El texto constitucional vigente puede ser caracterizado por: 1. una estructura no se reduce a una regulación de la conformación de los poderes estatales, además contiene "disposiciones sustanciales: una declaración de derechos y/o disposiciones teleológicas, que formulan «principios» y programas políticos"; 2. que cumple una "función de organizar a la sociedad civil (y no sólo a los poderes públicos) y modelar las relaciones sociales (y no sólo las relaciones políticas entre el Estado y los ciudadanos); 3. Que contiene un "proyecto detallado" de lo que se considera una "sociedad justa", por lo que todo juez se encuentra habilitado a aplicar directamente la constitución en cualquier controversia; y, 4. Establece un "control sobre la legitimidad constitucional de las leyes". Esto mediante una revisión de la adecuación formal, es 


\section{Principio de Efectividad en las Políticas Públicas referentes a la Protección Integral de la Niñez y Adolescencia en el Ecuador}

Vol. 2, núm. Esp., (2018)

Mariuxi Katherine Mata Echeverria

decir el respeto a los procedimientos constitucionales de formación de las leyes, y la adecuación sustancial, el respeto a los derechos y principios constitucionales.

Por tanto la preocupación del constituyente por resaltar los principios fundamentales de esta institución y por insistir en la responsabilidad del Estado y de la sociedad frente a la organización y protección de la niñez y adolescencia es evidentemente cumpliendo con la obligación de encontrar un nexo necesario entre los ciudadanos y los gobernantes.

Entrando en materia, la Constitución de la República del Ecuador señala que la Protección Integral en el Ecuador se regirá, para asegurar su cumplimiento, en la confección de sistemas especializados, particularmente menciona el Sistema Nacional Descentralizado de la Protección Integral de la niñez y adolescencia, lo que hace entender que su consecución, como lo manda la norma suprema, tiene el máximo fin del estado, que es cuidar integralmente de la niñez y adolescencia...

Por tanto los recursos para asegurar dicho cumplimiento y consecución de esta nueva institución, están igualmente señalados y garantizados en la misma. Siendo uno de las brechas más significativas entre la lírica y la realidad de la niñez y adolescencia en el Ecuador.

Por consiguiente para nuestro Estado, procura mantener un nexo, entre la Sociedad y el Gobierno, pero en algunos casos el propósito se desvía y fracasa.

Sin embargo es importante citar que, de acuerdo al texto constitucional, en que podría aplicarse otras normas por sobre la Constitución es cuando un tratado internacional de derechos humanos (ratificado por el país) reconozca "derechos más favorables". La eficacia normativa 


\section{Principio de Efectividad en las Políticas Públicas referentes a la Protección Integral de la Niñez y Adolescencia en el Ecuador}

Vol. 2, núm. Esp., (2018)

Mariuxi Katherine Mata Echeverria

directa de la Constitución, en lo que se refiere a derechos y garantías, se encuentra plenamente garantizada en el artículo 11.3. El mismo que estable que, Los derechos y garantías establecidos en la Constitución y en los instrumentos internacionales de derechos humanos serán de directa e inmediata aplicación por y ante cualquier servidora o servidor público, administrativo o judicial, de oficio o a petición de parte.

Para el ejercicio de los derechos y las garantías constitucionales no se exigirán condiciones o requisitos que no estén establecidos en la Constitución o la ley. Los derechos serán plenamente justiciables. No podrá alegarse falta de norma jurídica para justificar su violación o desconocimiento, para desechar la acción por esos hechos ni para negar su reconocimiento.

Los principios de eficacia normativa y de aplicación directa de la Constitución son considerados por algunos autores como los "pilares fundamentales del nuevo paradigma constitucional", esto convierte a toda "servidora o servidor público, administrativo o judicial" en intérpretes del texto constitucional, en tanto la Constitución es una norma jurídica con capacidad regulatoria y no exclusivamente un "programa político".

Bobbio, define a una norma jurídica (en consideración a su exterioridad e institucionalización) como aquella “cuya ejecución está garantizada por una sanción externa e institucionalizada". Esta definición asume que la "sanción" es el rasgo distintivo de una norma, en la Carta Magna establece la posibilidad de invocar sanciones mediante la resolución de un juez, y la eficacia como norma jurídica, sin negar las particularidades derivadas de su "jerarquía, finalidad y contenido". 


\section{Principio de Efectividad en las Políticas Públicas referentes a la Protección Integral de la Niñez y Adolescencia en el Ecuador}

Vol. 2, núm. Esp., (2018)

Mariuxi Katherine Mata Echeverria

Por tanto en la propuesta que derivará justamente de estos preceptos y postulados deberá contener sanciones y acciones en contra de la ineficiencia de la norma, por tanto que, las situaciones de hecho que constituyen violaciones individuales se encuentran estrechamente vinculadas a causas estructurales que por lo general tienen su raíz en la ausencia de políticas de prevención y protección general, colectiva, y no precisamente singular.

Así, muchas situaciones en el seno de una familia determinada son expresión de las carencias estructurales devenidas de la pobreza generalizada en la sociedad, por lo que la planificación general de la gestión social del Estado debe estar orientada a concebir y ejecutar eficazmente las políticas generales de protección especial para atender desde lo sustancialmente estructural a los niños individualmente considerados, y a sus familias.

\section{Conclusiones.}

La Protección especial como parte integrante e integradora de la Protección Integral no está dirigida al reconocimiento de situaciones jurídicas de Derechos humanos universales (salud, educación, vida digna, etc.), sino al reconocimiento del Derecho a ser protegido frente a situaciones de hecho que impiden el ejercicio de otros Derechos, o violentan Derechos, para restituir la condición y situación a parámetros normales de protección, y en consecuencia se trata de una atención positiva y preferencial de los Niños que se encuentran en estas situaciones especiales de desprotección.

Los Retos de la Administración Pública ante la Protección de la niñez y adolescencia en la nueva sociedad girarán en torno a los siguientes puntos críticos que evidencian los resultados obtenidos de la investigación. 


\section{Principio de Efectividad en las Políticas Públicas referentes a la Protección Integral de la Niñez y Adolescencia en el Ecuador}

Vol. 2, núm. Esp., (2018)

Mariuxi Katherine Mata Echeverria

Decía Antonio Carlos Gómez, No se trata ya de dar beneficios a los Niños, sino de acabar con los maleficios que no les dejan disfrutar de los beneficios que otros tienen. Y es así del cuadro que observaremos podemos entender lo que sucede en la situación irregular de la niñez y adolescencia en el Ecuador; la Administración Pública como responsable pretende direccionar todo su esfuerzo hacia la niñez y adolescencia pero sus resultados son limitados.

La evaluación realizada constituye una labor asistencial de carácter tuitivo, dirigida a ponderar la situación en que un menor se encuentra para evitar los riesgos que para la evolución de su personalidad, de tal situación se derivan para él.

La Sociedad Global representa un verdadero reto para la Administración Pública al momento de la implementación de Acciones Afirmativas en torno a la Protección de la Niñez y Adolescencia en un contexto universal.

También es necesaria aquella sensibilidad que permita identificar ciertas prácticas como características propias de ciertos sectores culturales de la comunidad, no perjudiciales para el desarrollo normal, aun cuando sean diferentes o incluso molestas para el resto de la colectividad.

La Sociedad Global exige que preparemos a los menores para unas formas de colaboración acentuadas en los campos de orden social, esto es en el deporte, el arte, las organizaciones culturales, es evidente la necesidad que tiene el Estado y la Sociedad de profundizar en las exigencias auténticas del objetivo a conseguir para encontrar el modo de actuarlo en la práctica de la educación reglada. 


\section{Principio de Efectividad en las Políticas Públicas referentes a la Protección Integral de la Niñez y Adolescencia en el Ecuador}

Vol. 2, núm. Esp., (2018)

Mariuxi Katherine Mata Echeverria

La unión del Estado Sociedad se hace emergente ante la realidad que vive la niñez y adolescencia, la creciente movilidad social, que es consecuencia inmediata de la transformación social de nuestros días, exige de los establecimientos educativos el que no puedan ser discriminatorios, porque sociológicamente surgen nuevas presiones que harán desaparecer esas tradicionales apariencias clasistas que aún subsisten, lamentablemente, y que constituyen un obstáculo para la armoniosa interacción de todos en función del bien común.

La creación de un control comunitario respecto a las instituciones que forman parte del sistema nacional descentralizado de la Niñez y Adolescencia, y de mecanismos que dinamicen la ejecución de los planes y programas de protección de los Derechos humanos de la Niñez y Adolescencia para el desarrollo integral de los mismos, sería la meta idónea para enrumbar el nexo del Estado y la Sociedad, no solo en el Ecuador sino en Latinoamérica a la luz de los convenios Internacionales y los encuentros, conversatorios que se hacen al respecto, pero con el Principio del Interés Superior del niño con la bandera de la Prioridad Absoluta, entendiéndose que todas las políticas públicas a implementarse deben ser enfocadas al bienestar de la niñez y adolescencia o por lo menos a interés de no causarles perjuicio en su desarrollo integral tendiendo de esta manera su Protección Integral.

\section{Bibliografía.}

DÍAZ RUIZ DE SIEKAVIZZA, A. (2014). NIÑOS, NIÑAS Y ADOLESCENTES VÍCTIMAS DE ABANDONO EN EL HOGAR MIGUEL MAGONE. GUATEMALA DE LA ASUNCIÓN: UNIVERSIDAD RAFAEL LANDÍVAR.

Observatorio de los Derecho de la Niñez y la Adolescencia. (2012). Estado de los derechos de la niñez y la adolescencia en Ecuador 1990-2011. Quito: UNICEF. 


\section{Principio de Efectividad en las Políticas Públicas referentes a la Protección}

Integral de la Niñez y Adolescencia en el Ecuador

Vol. 2, núm. Esp., (2018)

Mariuxi Katherine Mata Echeverria

Salanova Sánchez, E. (2010). Jean-Jacques Rousseau Respeto a la vida natural, la libertad y las diferencias individuales. Madrid: Educomunicacion.

UNICEF. (2006). CONVENCIÓN SOBRE LOS DERECHOS DEL NIÑO. Quito: Fondo de las Naciones Unidas para la infancia. 